\title{
A NARRATIVA E A HISTÓRIA DAS RELAÇÕES INTERNACIONAIS
}

\author{
Paulo Paiva*
}

\begin{abstract}
Resumo: Um título menos prático para este artigo talvez fosse escrito assim: Sobre as condições de possibilidade do ser humano conhecer a si mesmo e aos fenômenos coletivos que o envolvem e the são acessíveis por meio da leitura de textos. Não proporia tal absurdo ao editor, não obstante é esta a discussão central destas páginas que, porém, se encontra imersa na análise de uma obra que discorre sobre um tema de relações internacionais, neste caso entre o governo brasileiro do primeiro período Vargas (1930-45) e os judeus que pretendiam imigrar para o Brasil.
\end{abstract}

Palavras-chave: história das relações internacionais e historiografia; teoria da história; narração; Era Vargas e anti-semitismo.

\section{Nota ao Leitor}

Sendo este artigo constituinte de uma publicação especificamente internacionalista, busquei, mesmo em minhas considerações teóricas, tratar de temas que tocam as práticas analíticas de todas as disciplinas acadêmicas que podem ser agrupadas sob o rótulo de humanidades. Embora, por vezes, as citações que arrolei se dirijam diretamente aos historiadores, isto não deve impedir o leitor de perceber que os temas são comuns a todos que se interessam pelos fenômenos humanos e pretendem escrever sobre eles.

Cabe nesta nota ainda um outro esclarecimento. Um estudo definitivo sobre a imigração de judeus para o Brasil, entre 1930 e 1945, talvez remeta o pesquisador a arquivos em três continentes, exija dele a fluência em alguns idiomas, assim como alguns anos de reflexão. Assim, as palavras que aqui escrevo são melhor compreendidas como um esforço dialético que partiu das hipóteses colocadas por Tucci Carneiro quando a autora analisou a questão. E certamente não pretendo, com este arrazoado, por

\footnotetext{
* Licenciado em História - UniCEUB; Aluno Especial do Programa de Pós-graduação em História da UnB.
} 
fim à discussão do tema. Quando me oponho à construção proposta pela autora (e é só o que faço), procurei fazê-lo estando sustentado por números e argumentos de historiadores com respaldo acadêmico. O que pretendi, com esta breve exposição, foi confrontar algumas assertivas da autora supracitada que não correspondem ao que encontrei em minha ida aos arquivos, e nada mais do que isso.

\section{Introdução}

Embora nosso assunto seja de natureza imprecisa, façamos o possível para facilitar-lhe a compreensão. Consideremos primeiro, então, que a excelência moral é constituída, por natureza, de modo a ser destruída pela deficiência e pelo excesso, (...). O homem que evita e teme tudo e não enfrenta coisa alguma, torna-se covarde; em contraste, o homem que nada teme e enfrenta tudo torna-se temerário; ( ...) a moral e a coragem, portanto, são destruídas pela deficiência e pelo excesso, e preservadas pelo meio termo ${ }^{1}$.

A insigne mensagem trazida pelas palavras de Aristóteles que à humanidade serve como um conselho, a nós, historiadores, internacionalistas, sociólogos, antropólogos, deveria soar como um desafio. Desafio que se bifurca em duas direções: na de evitar a elevação das conclusões de nossas pesquisas a verdades inegáveis, e de evitar que nossa maneira de entender os fenômenos humanos seja reduzida aos arcabouços teóricos e metodológicos da disciplina em que nos graduamos ou com a qual decidimos trabalhar posteriormente. Ao dizer isto, o que pretendo é reeditar um alerta relacionado ao contínuo processo de especialização acadêmica, dentro das áreas do conhecimento denominadas por alguns como "ciências" humanas. Em sua esfera mais ampla, o assunto foi expresso de forma clara e direta por Albert Einstein:

\footnotetext{
Não basta ensinar ao homem uma especialidade. Porque se tornará assim uma máquina utilizável, mas não uma personalidade. É necessário que adquira um sentimento, um senso prático daquilo que vale a pena ser empreendido, (...). A não ser assim, ele se assemelhará, com seus conhecimentos profissionais, mais a um cão ensinado do que uma criatura harmoniosamente desenvolvida. Deve aprender a compreender as motivações dos homens, suas quimeras e suas angústias para determinar com exatidão seu lugar exato em relação a seus próximos e à comunidade.

(...) os excessos do sistema de competição e de especialização prematura, sob o falacioso pretexto da eficácia, assassinam o espírito, impossibilitam qualquer vida cultural e chegam a
}

\footnotetext{
${ }^{1}$ ARISTÓTELES. Ética a Nicômaco. Brasília: Editora UnB, 1985, p. 37.
} 
suprimir os progressos nas ciências do futuro. É preciso, enfim, tento em vista uma educação perfeita, desenvolver o espírito crítico na inteligência do jovem² ${ }^{2}$.

Quem está familiarizado com as idéias de Einstein percebe rapidamente o viés político-científico que é característica marcante de sua longa luta pela paz e pelos valores do humanismo. Não obstante, gostaria de destacar aqui uma outra dimensão do trecho acima. Einstein nos diz que uma "educação perfeita" demanda o conhecimento (ou, diria eu, o esforço contínuo por obtê-lo) das "motivações do homem, suas quimeras e suas angústias". Sendo assim, afigura-se claro que as motivações essenciais dos seres humanos não são objeto apenas da filosofia ou da psicologia, mas tem de ocupar também a mente dos estudiosos que refletem sobre as relações entre os homens, com vistas a tornarem-se intérpretes mais conscientes. Historiadores, internacionalistas, sociólogos e antropólogos são obrigados a reflexões sobre suas próprias motivações, confrontados pela possibilidade de seus modelos realistas de compreensão se oporem frontalmente às possibilidades de apreensão do conhecimento pelo psiquismo humano. O que defendo aqui é a necessidade de se observar que tais "motivações", "quimeras" e "angústias" são inevitavelmente históricas; fato que apresenta conseqüências para os que estudam os fenômenos humanos - tanto individuais quanto coletivos - que não podem ser ignoradas. A primeira destas conseqüências é que, quando estudamos "fatos" do passado, temos que observar a historicidade dos agentes que produziram tais "fatos" e não julgá-los anacronicamente. A segunda destas consequiências - e talvez a mais polêmica - é que nós (intérpretes) também somos providos de uma história da qual não podemos nos desvencilhar e que influenciará amplamente nossos entendimentos sobre os objetos que escolhemos estudar (nesse sentido, poderíamos acrescentar a necessidade da auto-crítica no espírito desse “jovem”). Há ainda uma terceira conseqüência; para que compreendamos razoavelmente a condição histórica do nosso objeto e de nossa possibilidade de entendê-lo, uma "formação multidisciplinar" "torna-se indispensável. Nas palavras de Norbert Elias, é necessário:

derrubar as cercas artificiais que hoje erigimos no pensamento dividindo seres humanos em várias áreas de controle: os campos, por exemplo dos psicólogos, dos historiadores e dos

\footnotetext{
${ }^{2}$ EINSTEIN, A. Como vejo o mundo. Rio de Janeiro: Nova Fronteira, 1981, pp. 29-30.

${ }^{3} \mathrm{O}$ que proponho aqui não é que o intérprete dos fenômenos humanos gradue-se em uma infinidade de disciplinas acadêmicas, mas algo que seria mais bem expresso pela palavra erudição.
} 
sociólogos. As estruturas da psique humana, as estruturas da sociedade humana e as estruturas da história humana são indissociavelmente complementares só podendo ser estudadas em conjunto. Elas não existem e se movem na realidade com o grau de isolamento presumido pelas pesquisas atuais. Forma ao lado de outras estruturas, o objeto de uma única ciência humana ${ }^{4}$.

A idéia que defendo através destas citações não é, de modo algum, apenas uma lucubração afastada da prática. Pelo contrário, considero que a atenção sobre, por exemplo, as condições de possibilidade dos seres humanos conhecerem a si mesmos e aos fenômenos que os rodeiam e afetam poderia ter nos poupado de décadas de modelos teleológicos de compreensão dos fenômenos humanos e de pretensões ilusórias ao conhecimento positivo. Nestas poucas páginas, pretendo colocar algumas reflexões a respeito do relacionamento entre o intérprete dos fenômenos humanos e suas fontes documentais, e as consequiências deste relacionamento para pretensões positivistas dentro das "ciências" humanas. Em seguida, tentarei trazer todas essas considerações abstratas para um plano concreto, através de uma crítica dirigida a um trabalho onde pude perceber afirmações categóricas do que "realmente aconteceu", embasadas numa prática analítica reducionista. Neste trabalho ${ }^{5}$, existe uma análise dos trâmites que regiam a imigração para o Brasil, entre 1930 e 1945, no que estes tocavam as pretensões imigratórias dos judeus. Análise esta que, por não ter se detido com extremo cuidado sobre as relações internacionais do período e sobre o plano mais abrangente do processo imigratório, produziu conclusões que só posso classificar de absurdas, conclusões que, por terem sido reeditadas recentemente ${ }^{6}$, mostram-nos a urgência de sua correção.

\section{O humanista enquanto um "escultor" do discurso}

As considerações que farei a seguir são embasadas em um entendimento do psiquismo humano que considera, em larga medida, a influência dos processos inconscientes. Fazendo isso, estarei seguindo a trilha aberta por Hayden White, quando este autor considerou que os processos que regem a produção dos sonhos são análogos aos que definem a construção de um discurso histórico ${ }^{7}$. Em verdade, propor essa

\footnotetext{
${ }^{4}$ ELIAS, N. A Sociedade dos Indivíduos. Rio de Janeiro: Jorge Zahar, 1990, p. 38.

${ }^{5}$ CARNEIRO, M. L. T. O Anti-semitismo na Era Vargas. São Paulo: Brasiliense, 1988.

${ }^{6}$ Refiro-me aqui à edição de lavra da Editora Perspectiva que foi veiculado em 2001.

${ }^{7}$ WHITE, H. Trópicos do Discurso: ensaios sobre a crítica da cultura. São Paulo: Editora da USP, 1994, pp. 124-132.
} 
hipótese explicativa não demanda um grande insight analítico, uma vez que o próprio Freud deixa clara a proximidade entre os processos oníricos e os encadeamentos intelectuais que nos governam enquanto despertos. No sentido de ilustrar tal idéia na obra psicanalítica, transcreverei um trecho do livro A Interpretação dos Sonhos:

\begin{abstract}
A função psíquica que empreende o que descrevemos como elaboração secundária do conteúdo dos sonhos deve ser identificada com a atividade de nosso pensamento de vigília. ${ }^{8}$
\end{abstract}

Feito isso, buscarei externar, através das palavras do próprio White, como em sua análise tropológica é feita tal aproximação conceitual entre a história e a psicanálise. Em seguida, defenderei a opinião de que podemos ir ainda mais longe do que ele foi em sua apropriação da teoria freudiana. Embora o tamanho das citações que farei exceda o usual, considero que as idéias desenvolvidas nelas são primordiais para o objetivo deste tópico; a saber, provar que a subjetividade historicamente determinada do intérprete é uma presença inevitável nas análises que buscam compreender os fenômenos humanos, ela sendo reconhecida ou não. Além disso, concordo que "na exposição da problemática filosófica a brevidade não simplifica as coisas, mas as complica, em conseqüência, as torna pouco compreensíveis quando não completamente incompreensíveis." 9

\begin{abstract}
O historiador - como qualquer autor de prosa discursiva - molda os seus materiais. Pode moldálos de maneira a adaptá-los a uma estrutura de idéias preconcebidas do tipo Hegel e Marx, ou de molde igual ao do romancista na função de narrador de uma estória. Mas, em ambos os casos seu relato dos fenômenos sobre exame se desenvolverá em pelo menos dois níveis de sentido, que podemos comparar aos níveis manifesto e latente de um sonho ou os níveis literais e figurativos da literatura imaginativa em geral. ${ }^{10}$

(...) a conseqüência é uma distorção de todo o campo factual considerado como uma totalidade de todos os eventos que, segundo a nossa percepção ocorrerão dentro dos seus limites. Essa distorção pode parecer mais compreensível do que o campo de eventos em seu estado não processado ou processado apenas em forma crônica mas ela é mais compreensível apenas com relação ao modelo conceitual que sancionou a sua distorção desta maneira e não de outra. É em resposta a esse modelo conceitual pressuposto que o historiador "condensa" os seus materiais (isto é, inclui alguns eventos e exclui outros), “desloca” alguns fatos para a periferia ou para o
\end{abstract}

\footnotetext{
8 FREUD, S. A interpretação dos Sonhos. Rio de Janeiro: Imago, 2001, p.483. Remeto o leitor especialmente à edição indicada aqui, pois, esta é traduzida direto do alemão e são notórios os problemas da tradução para o inglês (da qual os leitores de língua portuguesa são dependentes). Trechos análogos podem ser lidos nas páginas 476 e 490, também desta edição.

${ }^{9}$ REALE, G. História da Filosofia. São Paulo: Paulus, vol. I, p. 5.

${ }^{10}$ WHITE, H. Trópicos do discurso: ensaios sobre a crítica da cultura, p.124.
} 
plano de fundo e leva outros para mais perto do centro; codifica alguns como causas e outros como efeitos; une alguns e separa outros - a fim de "representar" a sua distorção como uma distorção plausível ; e cria, um outro discurso, uma "elaboração secundária" que caminha ao longo do nível mais obviamente representacional do discurso que em geral se afigura como uma fala direta ao leitor e fornece as bases cognitivas explícitas (a "racionalização") para a forma manifesta do discurso em geral. ${ }^{11}$

Existe ainda, em minha opinião, um outro processo decisivo para a formação dos sonhos - a sobredeterminação ${ }^{12}$ - que se pode relacionar ao constructo discursivo das "ciências" humanas. Aplicando tal raciocínio à relação que existe entre o discurso dos humanistas e as fontes que o embasam, facilmente notaríamos que são exatamente as hipóteses do autor que encontram maior número de apoios nas fontes históricas que ganham expressão discursiva; o texto seria, então, uma composição das hipóteses subjetivas do intérprete ${ }^{13}$ que foram sobredeterminadas pelo arquivo. É exatamente por isso, que o recurso a fontes variadas torna-se indispensável, inclusive a fontes mais freqüentemente trabalhadas por outras disciplinas. Pois será por meio desta polifonia vinda dos arquivos que se poderão confrontar nossas hipóteses prévias e perceber sua validade ou inadequação.

Poderíamos dizer ainda que as hipóteses formuladas pelo intérprete têm seus limites condicionados por uma "instância censora" 14 . Tal instância censora do discurso dos humanistas seria composta por todas as influências e coerções que o historiador sofre ou sofreu ao longo de sua experiência de vida (intelectual, acadêmica, sóciopolítica, enquanto membro de uma nação, de uma classe social ou como individuo). Aqui poderíamos inserir um exemplo que antecipa minhas considerações sobre o trabalho de Tucci Carneiro. A autora não considerou, por exemplo, que a quantidade de informação sobre o que se passava nos campos de concentração nazistas que nós temos hoje é imensamente maior que a que tinham os homens que tratavam da imigração para o Brasil no período abordado por ela. Ou seja, a profunda indignação com o destino que

\footnotetext{
${ }^{11}$ Idem, pp.129-30.

${ }^{12}$ FREUD, S. A interpretação dos Sonhos, p. 283. Neste curto trecho, Freud dá uma idéia clara do que considera um elemento onírico sobredeterminado: "o sonho é, antes construído por toda massa de pensamento oníricos, submetido a uma espécie de processo manipulativo em que os elementos que têm apoios mais numerosos e mais fortes adquirem o direito de acesso ao conteúdo manifesto".

${ }^{13} \mathrm{O}$ que chamo de hipóteses subjetivas aqui é análogo às múltiplas "projeções de sentido" que Gadamer ressalta serem a única forma de aproximar-se do objeto histórico. In: GADAMER, Hans-Georg. Verdade e Método. Petrópolis: Vozes, 1997, Parte II, pp. 401-2.

${ }^{14}$ Para uma compreensão detalhada do conceito freudiano de censura, ver: FREUD, S. O Ego e os mecanismos de defesa. Rio de Janeiro: Civilização Brasileira, 1982, pp.59-90.
} 
os judeus tiveram (da qual também compartilho) impediu que a autora interpretasse os documentos epocais com uma perspectiva de estranhamento.

O papel exercido pelo historiador (amplio as questões aqui colocadas para que alcancem os demais "humanistas") enquanto um escultor do discurso histórico foi expresso de forma mais apropriada por Chartier e White do que seria por mim:

\footnotetext{
A obra histórica representa uma tentativa de mediação entre o que eu chamarei de campo histórico, o registro histórico não processado, outros relatos historiográficos e um público. ${ }^{15}$

Por suas eleições, suas seleções, suas exclusões, o historiador atribui um sentido novo as palavras que tira do silêncio dos arquivos. ${ }^{16}$
}

Não se trata aqui, e isto gostaria de deixar muito claro, de um ataque "niilista" ao valor das narrativas produzidas pelos "humanistas". Em palavras infinitamente mais experientes que as minhas, o que enxergo como possível para um escritor que se interesse pelos fenômenos humanos registrados por textos (ou seja, praticamente todos), é uma abordagem "consciente, refletida, vale dizer, desvinculada de qualquer epistemologia realista, oposta mesmo à ilusão de representar 'o que aconteceu'"17.

A polêmica em torno de declarações como esta tem ocupado os teóricos da historiografia, nas palavras de Carlo Ginzburg: “A redução da historiografia à retórica é, há três décadas, o cavalo de batalha de uma extensa polêmica antipositivista com implicações mais ou menos abertamente céticas ${ }^{18}$ ". A discussão sobre a presença - em menor ou maior grau - da retórica no discurso historiográfico, remete-nos, necessariamente, até a mais crucial das discussões das "ciências" humanas. De um lado, estão os que entendem que a produção intelectual de um intérprete acerca de um determinado objeto abstrato é subjetiva; de outro, os que consideram possível afastarem todos os seus juízos ao abordarem o objeto que lhes interessa.

Considero - ao contrário dos "objetivistas" - improvável a possibilidade de um homem poder cindir-se; em um ente envolvido em uma diversidade de relações (sociais, econômicas, culturais, políticas, profissionais e pessoais, em suma, históricas), e, em um outro, ausente da realidade e que só existe no plano das abstrações acadêmicas. Em

\footnotetext{
${ }^{15}$ WHITE, H. Meta-história, p. 21.

16 CHARTIER, R. Uma crise na história? A história entre a narração e o conhecimento. In: PESAVENTO, S. J. (Org.). Fronteiras do milênio. Porto Alegre: Ed. UFRGS, 2001, p.117.

${ }^{17}$ LACERDA, S. História, narrativa e imaginação histórica. In: SWAIN, T. N. (Org.) História no Plural. Brasília: Ed. UnB, 1993, p.26.
} 
verdade, as modalidades de escrita que se afastam da primeira pessoa do singular, apenas disfarçam a subjetividade do autor. Stephen Bann, ao refletir sobre o posicionamento de Roland Barthes, dirá, no trecho abaixo, algo similar ao que defendo neste parágrafo:

a "deficiência de signos do historiador" e, em particular, a exclusão do "eu" do texto, garantem nada mais que a ilusão da objetividade, (...). Optando por excluir o "eu" da narrativa histórica, ele não está fazendo mais do que adotar uma "persona objetiva", que certamente não o protegerá de uma inflexão pessoal do texto que está escrevendo. ${ }^{19}$

O que se reivindica aqui não é nada além do reconhecimento da condição primariamente histórica do intérprete dos textos e documentos que transportam até nós construções referentes a um passado perdido no tempo (ou, referentes a um fenômeno complexo $^{20}$, mesmo que contemporâneo). Tal condição, inevitavelmente histórica de apreender os fenômenos humanos, nos foi destacada pelo trabalho fundador de Gadamer, quando este se apropriou da hermenêutica histórica de Heidegger ${ }^{21}$. Citarei algumas palavras de Gadamer, com a certeza de que se afigurará claro ao leitor que mesmo o objeto de investigação do humanista é construído por sua subjetividade:

\begin{abstract}
Nas ciências do espírito o interesse investigador que se volta para a tradição é motivado, de uma maneira especial, pelo respectivo presente e seus interesses. Somente a motivação do questionamento é que deveras se constitui, como tal, o tema e o objeto da investigação.(...) Em si, um tal objeto não existe de modo algum. É isso o que distingue as ciências do espírito das da natureza.(...) não faz sentido falar-se de um conhecimento completo da história. E por isso não é adequado, em última análise, falar de um "objeto em si" ao qual se orienta a investigação ${ }^{22}$.
\end{abstract}

De minha parte, entendo que os trabalhos germinais citados ao longo destas páginas impossibilitam nossa permanência à sombra da ilusão da objetividade. Neste sentido, seria producente que a esperança do afastamento absoluto em relação ao objeto fosse descartada, e que esta fosse substituída por uma abordagem permeada pela auto-

\footnotetext{
${ }^{18}$ GINZBURG, C. Relações de força: história, retórica e prova. São Paulo: Cia das Letras, 2002, pp.478.

${ }^{19}$ BANN, S. As invenções da história: ensaios sobre a representação do passado. São Paulo: Ed. USP, pp.79-80. O grifo é meu.

20 Esse termo absolutamente vago que uso aqui, "fenômeno complexo", foi escolhido exatamente para indicar que me refiro a relações entre os homens que não podem ser contidas em "conceitos" do tipo sociocultural ou socioeconômico.

${ }^{21}$ GADAMER, H-. G. Verdade e método. Parte II, pp. 400-449.
} 
análise constante do intérprete em relação às suas possíveis projeções de sentido sobre o texto de "interesse humanístico". Afastando-me da objetividade ilusória e da especialização acadêmica radical - que reduz o humanista a técnico - opto por uma abordagem do "objeto" histórico que leve em conta os avanços no conhecimento dos fenômenos humanos conseguidos por outras áreas de estudo; como enunciou Schorske:

\footnotetext{
Hoje, os estudantes de história participam de seminários de arte e literatura - ou até de treinamento psicanalítico - para adquirir técnicas de análise do assunto que desejam explorar do ponto de vista histórico.(...) Uma geração educada desta maneira, como todos sabemos, está apenas começando a produzir obras que combinam a análise rigorosa com a textura histórica bem trançada. ${ }^{23}$
}

Dedico-me a estas considerações teóricas por considerá-las indispensáveis para o entendimento das possibilidades do conhecimento objetivo nas "ciências" humanas; além disso, creio que um posicionamento do autor com relação ao seu entendimento teórico-metodológico da disciplina acadêmica em que trabalha, só favorece as possibilidades de apropriação e crítica por parte do leitor.

\section{As relações internacionais do período Vargas enquanto impossibilidade para a hipótese do anti-semitismo}

\section{Tese: A construção do anti-semitismo na Era Vargas}

Depois de oferecer-nos uma sucinta história do anti-semitismo em território nacional, Tucci Carneiro passa a tratar do período que é objeto de seu livro, ou seja, o primeiro período Vargas, contido entre 1930 e 1945. De acordo com as convicções da autora, este período foi palco para um anti-semitismo que só pode ser explicado se aceitarmos que a administração Vargas sofreu extensa influência de idéias nazistas e fascistas, que tinham como berço a Europa do "entre-guerras". Acompanhando a construção da autora, podemos definir o anti-semitismo do período Vargas como decorrente, em suma, de dois processos interatuantes. Em primeiro lugar, o golpe de

\footnotetext{
${ }^{22}$ Idem, p.427.

${ }^{23}$ SCHORSKE, C. F. Pensando com a história: indagações na passagem do modernismo. São Paulo: Cia das Letras, 2000, pp.254-5.
} 
1930 e a futura instalação de um governo autoritário favoreceram o avanço de uma mentalidade xenófoba. Sobre este "estado de coisas", uma extremada influência ideológica nazi-fascista passou a direcionar a política imigratória dos órgãos competentes, que externaram uma disposição de ódio contra o grupo judeu. Dentro deste quadro, a autora considera que os judeus foram classificados como indesejáveis por sua "etnia" ou "raça" (definição que na época, ainda não encontrava a resistência que vemos hoje), o que compõe, pelo menos no tocante à estruturação do pensamento anti-semita, o Governo de Vargas e o Terceiro Reich.

O que sustenta esta construção são documentos diplomáticos e consulares, periódicos e literatura corrente na época. Entre estes documentos, existe um que, em particular, compõe com a tese da autora. Trata-se da circular secreta número 1.127, expedida pelo Itamaraty em 7 de julho de 1937, que vigorou como parâmetro para a imigração de "semitas" até 28 de setembro do ano seguinte, quando foi substituída pela circular secreta número 1.249, de caráter consideravelmente mais maleável. Em linhas gerais, pode se resumir assim o conteúdo da circular 1.127, que, no entendimento da autora, é prova inconteste de um anti-semitismo de cunho racial instalado no período Vargas. Por aplicação desta circular, os consulados estavam proibidos de conceder vistos em passaportes de indivíduos de origem semita. Tratando-se de pessoas de destaque na sociedade e no mundo dos negócios, os consulados deviam consultar a Secretaria de Estado antes de recusar o visto ${ }^{24}$. Além da supracitada circular, o vínculo ideológico entre os intelectuais orgânicos de Vargas e o Reich é construído através de manifestações isoladas de indivíduos dentro do corpo estatal e, principalmente, por meio de opiniões expressas em periódicos ligados a grupos de extrema direita.

E é sustentada por estas fontes que Tucci Carneiro escreve, ao considerar a estrutura anti-semita dos órgãos competentes, que no Brasil não tivemos campos de concentração, "realmente não chegamos a tanto, mas existiram entre nós, o paraíso dos trópicos, condimentos necessários que quase nos transformou num purgatório nazista",25. Em um trecho posterior, ela vai considerar que "o holocausto deixou marcas profundas, mas as idéias e práticas anti-semitas do governo Vargas também fizeram vítimas" ${ }^{26}$. As hipérboles que permeiam todo o longo livro de Tucci Carneiro encontram seu exemplo final em uma pergunta: “quantos seres humanos poderiam ter sido

\footnotetext{
${ }^{24}$ Uma transcrição do texto original pode ser encontrada no livro em discussão, p.168.

${ }^{25}$ CARNEIRO, M. L. T. O Anti-semitismo na Era Vargas (1930-1945), pp. 21-2.

${ }^{26}$ Idem, p.30.
} 
poupados do terror nazista se o governo Vargas não tivesse assumido uma política de restrição à imigração 'semita'?", 27

\section{Antítese: Alguns elementos que permitem um repensar acerca da hipótese do anti- semitismo na administração Vargas}

Estes trechos são representativos da tendência, sob meu ponto de vista, quase infantil assumida pela autora, ao julgar o Itamaraty pelas mortes de judeus nos campos de concentração nazistas. Essas declarações apaixonadas tornam-se particularmente arbitrárias e incorretas, ao considerarmos que a legislação americana não diferia da brasileira no tocante à imigração. Mesmo assim, não encontramos nas estantes das bibliotecas livros que dão a entender que Roosevelt fosse um favorecedor consciente do assassinato de judeus. Pois, se restrição à imigração de "semitas" for indicativo de simpatia e alinhamento com o estado nazista, então, certamente, os americanos eram mais intensamente germanófilos que o governo Vargas, uma vez que lá a legislação foi cumprida mais severamente que aqui.

Talvez a autora tenha considerado a administração Vargas anti-semita por suas pesquisas a terem conduzido a considerar, em primeiro plano, os casos individuais, as ocorrências particulares e as expressões isoladas de opinião. Este tipo de fonte; opiniões de jornalistas e editores tendenciosos, conferências de líderes religiosos exaltados, lembranças de imigrantes que tem sua memória confrontada por décadas, não nos dão uma visão global da prática imigratória do período Vargas e das diretrizes que a guiavam. Em verdade, considerações generalizantes baseadas neste tipo de evidência, nos colocam frente a um entendimento histórico fragmentado que, inevitavelmente, desembocará em análises simplistas e que reduzem a complexidade dos fenômenos estudados.

Antes, porém, de tratar da análise da autora em relação à imigração de judeus para o Brasil, creio ser indispensáveis algumas palavras sobre seu equívoco ao interpretar o "contexto" que era pano de fundo para a subida de Getúlio ao poder. A autora aceita como verdadeira a explicação economicista que reduz o movimento revolucionário de 1930 a uma substituição de classes na cúpula decisória do país

\footnotetext{
${ }^{27}$ Ibidem, p.502.
} 
(substituição essa, diga-se de passagem, considerada inevitável pela teleologia marxista). Por exemplo, explica esta substituição como "a decadência da oligarquia rural e a ascensão do comércio e da indústria, ou seja, a consequiência de uma fase de transformações onde a aristocracia rural, para sobreviver, se viu obrigada a dividir os privilégios com os novos ricos" 28 .

Este modelo explicativo, de tipo reducionista-classista que enxerga os fenômenos humanos como meras conseqüências das demandas econômicas, é o resultado de uma transposição para a realidade brasileira de uma explicação mais adaptável à realidade européia ${ }^{29}$. No livro citado, o autor nos mostra claramente como os incipientes setores industriais do país se encontravam afastados dos aliancionistas. Ao considerar que o corpo revolucionário se encontrava em Minas Gerais, no Rio Grande do Sul e, em menor escala no PD paulista, as colocações de Fausto batem de frente com a aceitação teórica de Tucci Carneiro. Nos mostra que tanto os grupos industriais do Rio de Janeiro quanto a FIESP externaram apoio a Júlio Prestes (candidato de Washington Luís), considerando que a hipótese de que a oposição aos tradicionais republicanos paulistas eram expressões dos interesses industriais é, em nada, verossímil. O autor escreve ainda que a característica antiindustrial pode ser observada nos golpistas gaúchos (PRR), uma vez que tanto os antigos chefes políticos do estado, Borges de Medeiros e Assis Brasil, como os novos expoentes da política gaúcha como Getúlio Vargas e João Neves da Fontoura, tinham laços que os ligavam fortemente ao meio rural $^{30}$. No caso do PD paulista, fundado em 1926, escreve que embora tenha sido adversário de Washington Luís, não se aproximava por isso dos industriais, tendo, inclusive, uma postura antiindustrial declarada ${ }^{31}$. O caso mineiro é, segundo Fausto, ainda mais claramente oligarca. Classificando Antônio Carlos, Arthur Bernardes, Francisco Campos e Virgílio de Mello Franco como revolucionários oligarcas $^{31}$. Sendo assim, só posso considerar que tal entendimento contextual do período deriva de um modelo teleológico de compreensão dos fenômenos históricos, modelo este que não demanda corroboração através de "fatos" históricos, uma vez que

\footnotetext{
${ }^{28}$ Ibidem, p. 127.

${ }^{29}$ Fausto, B. A Revolução de 1930: Historiografia e História. São Paulo: Cia das Letras, 1997, p. 11.

${ }^{30}$ Idem, p. 57.

${ }^{31}$ Ibidem, p. 49.

${ }^{31}$ Ibidem, p. 61.
} 
projeta sobre o campo factual rupturas de ordem econômica, que são consideradas inevitáveis para o caminhar de qualquer sociedade humana. ${ }^{32}$

Passemos, finalmente, ao objetivo principal deste tópico, a saber, demonstrar a impossibilidade de um alinhamento político-ideológico entre Brasil e Alemanha, que se manifestasse de forma tácita na política imigratória. Para demonstrar o quanto o "antisemitismo na era Vargas" afigura-se inverossímil, começo por fazer um arrazoado das relações internacionais entre 1880 e os anos anteriores à Segunda Guerra. Podemos dividir as relações internacionais que antecedem o período em questão (a era Vargas) em duas configurações políticas distintas. A primeira, compreendida entre 1880 e 1914 , e a segunda, a do período posterior ao final da Primeira Guerra até a década de 1930.

Até 1914, as relações internacionais estavam sob orientação da ideologia liberal. Embora a economia mundial fosse regida pela doutrina dos custos comparados, a orientação aduaneira deslocava-se no sentido do não intervencionismo estatal. Tal mentalidade fica clara ao considerarmos, por exemplo, que os acordos de alfândega duravam dez anos ou mais ${ }^{33}$. Percebemos pequenos níveis de protecionismo, porém, estes são mais bem compreendidos como pressões vindas das nações imperialistas que lutavam entre si pelas áreas de influência comercial. Neste primeiro período, os europeus levavam as vantagens de terem partilhado os espólios do saque à África e conseguido estabelecer uma presença majoritária do capital estrangeiro investido na América Latina. Por exemplo, no começo do século, 5/6 da rede ferroviária brasileira era explorada por empresas particulares inglesas, francesas e belgas ${ }^{34}$. A situação dos setores de energia e exploração de matéria-prima não se mostrava diferente.

Voltando ao nosso objeto principal, a imigração, percebemos ainda mais nitidamente a mentalidade liberal. As fronteiras americanas estavam completamente abertas, na primeira década do século, por exemplo, entraram nos Estados Unidos cerca de 8.500.000 pessoas, sendo que o posterior ano de 1914 foi o segundo do período em número de imigrantes, entraram por fronteiras americanas neste ano 1.218.000 pessoas $^{35}$. Durante estes mesmos quinze anos, a Inglaterra recolheu em seus portos levas

\footnotetext{
${ }^{32}$ Uma simples tentativa de listar as inúmeras análises marxistas que projetaram anacronismos sobre os campos factuais que estudaram, demandaria muito mais páginas do que as de que disponho. Entretanto, acredito existir lugar nesta nota para um comentário de Nicole Loraux: "houve um tempo em que os menos marxistas dos historiadores da Grécia antiga povoavam tranqüilamente as cidades de 'capitalistas' e 'proletários"'. In: NOVAES, A. Tempo e História. São Paulo: Cia das Letras, 1992, p. 58.

${ }^{33}$ RENOUVIN, P. e DUROSELLE, J. B. Introdução à História das Relações Internacionais. São Paulo: Difusão Européia do Livro, 1967, p. 77.

${ }^{34}$ Idem, p. 94.

${ }^{35}$ Historical Statistics, pp.56-7. In: http: //www.ins.usdoj.gov/graphics/aboutins/statistics/legistics/htm.
} 
de imigrantes do leste europeu, em grande parte judeus que fugiam dos pogroms russos do início do século.

O período de guerra, 1914 a 1918, mudou todo o panorama das relações econômicas e diplomáticas entre as nações. A instável paz conseguida em Verssailhes fazia com que todos na Europa protegessem suas indústrias e agriculturas; agravou-se o protecionismo em meio à gênese de nacionalismos e isolacionismos que marcariam o período seguinte. A partir da década de 1920, o nacionalismo xenófobo avança alimentado pela Revolução Russa de 1917 e estende seus "tentáculos" sobre todas as relações internacionais. A guerra, porém, não transformou apenas a ideologia que regia as decisões estatais, ela reposicionou a importância, dentro da economia internacional, das nações industrializadas. Houve, em suma, uma reorganização da influência econômica e política que as nações ricas impunham sobre as periféricas. Durante a guerra, os banqueiros britânicos e franceses perderam todo o dinheiro que tinham a receber da Rússia, Áustria-Hungria e Império Otomano. Suas exportações foram arrasadas pelo esforço de guerra e as conseqüentes importações apresentaram-se opressivas para a economia das nações da Europa ocidental. As vantagens obtidas pela economia dos Estados Unidos devido à condição européia são externáveis através de um número; em 1914, os americanos deviam cerca de 4 milhões de dólares a instituições de crédito européias; em 1919, os europeus deviam mais de 10 milhões de dólares a casas de crédito americanas. Os prejuízos sociais, na estrutura industrial e de transporte das nações européias, somados ao pagamento da dívida supracitada, criaram uma situação de imobilidade econômica nas nações em questão. Por isso, tornou-se impossível a continuação da política de investimentos e influência econômica nos países periféricos, por parte das potências industriais européias. Ainda no período de 1925 a 1929, a Europa e a América Latina eram inundadas por investimentos yankes ${ }^{36}$.

Dentro deste quadro, os Estados Unidos, pela primeira vez, tornaram-se o maior parceiro comercial do Brasil. As importações de produtos americanos, que nunca passaram de 10 milhões, chegaram a 17 milhões de dólares antes do final da Guerra ${ }^{37}$. Além da situação econômica internacional no entre-guerras, existiam forças internas que favoreciam o avanço da influência comercial americana. Por tudo que escreve Muniz Bandeira, torna-se evidente a preferência do presidente Epitácio Pessoa pelo

\footnotetext{
${ }^{36}$ RENOUVIN, P. e DUROSELLE, J. B. Introdução à História das Relações Internacionais, p. 137.

37 BANDEIRA, M. A Presença dos Estados Unidos no Brasil. Rio de Janeiro: Civilização Brasileira, 1978, p. 191.
} 
investimento de capital americano em detrimento do europeu. Em dois anos, o novo governo contraiu 75 milhões em empréstimos, regidos por juros de $8 \%$, os mais onerosos já registrados. ${ }^{38}$

Embora plenamente engajado na economia internacional, no plano interno, os Estados Unidos, sob o republicano Harding experimentou uma crescente postura isolacionista ${ }^{39}$. Sellers desenvolve um raciocínio que nos colocará de volta à reflexão sob o objeto de estudo deste artigo. Ele escreve que "Mesmo sendo impossível se isolar dos assuntos externos, os americanos podiam controlar a imigração" ${ }^{, 40}$. Ao tratar o motivo desta mudança de atitude americana quanto à imigração, ele coloca que “Durante a guerra e no 'pavor vermelho' que a ela se seguiu, nativismo e xenofobia atingiram seu auge"41. A expressão legislativa desta mudança de mentalidade é externada por leis que restringiam a imigração. As leis de 1921 e $1924^{42}$ mostraram sua atuação por meio dos reduzidos números totais de imigrados dos anos posteriores à sua homologação. Enquanto em 1921 entraram nos Estados Unidos 805.000 imigrantes, o ano seguinte teve seu contingente reduzido para 310.000 pessoas. A publicação seguinte, de 1924, não teve efeito menos expressivo ao reduzir o número de entrados que alcançou 707.000 no ano da publicação e que no ano seguinte, em vigência desta, foi reduzido para 294.000 pessoas.

Embora passe a impressão de estar me afastando do tema do "anti-semitismo na era Vargas", escrevo estas linhas a respeito das relações internacionais e da imigração para a América do Norte com o intuito de esclarecer a abrangência que alcançou o fenômeno do nacionalismo exacerbado e xenófobo. Em verdade, nos anos 1920 e 1930, este fenômeno podia ser observado tanto na Europa quanto na América. Sendo assim, para onde se virasse o "intelectual de imigração" em busca de modelos de identificação, ele iria deparar-se com o temor em relação ao diferente, ao estrangeiro.

Em site oficial do governo americano, que comenta de uma perspectiva histórica a legislação do período, vemos como o sistema de quotas estabelecido era especialmente prejudicial aos judeus:

\footnotetext{
${ }^{38}$ Idem, p. 204.

39 SELLERS, C. Uma Reavaliação da História dos Estados Unidos. Rio de Janeiro: Jorge Zahar, 1985, p.312.

${ }^{40}$ Idem, p. 314.

${ }^{41}$ Ibidem.

42 Quota Law of May 19, 1921 e Immigration Act of May 26, 1924. In: http: //www.ins.usdoj.gov/graphics/aboutins/statistics/legistics/htm.
} 
This policy favored the older Anglo-Saxon and northean European stock, who were more numerous than immigrants from southern and eastern Europe (...). At the same time, thousands of persons sought to flee totalitarian regimes like that in Nazi Germany. Since American immigration policies failed to distinguish between immigrants and refugees in the quota counts, most of the refuges (principally Jews) were barred from coming to the United States. ${ }^{43}$

Uma característica pode ser encontrada em qualquer um dos nacionalismos xenófobos da época, tanto nos de orientação totalitária, como nos democráticos; o temor extremado em relação ao avanço comunista. Mesmo não sendo comunista, Getúlio estava longe de ser permissivo aos interesses americanos como o foram seus antecessores, Epitácio Pessoa e Washington Luís. Em 1934, Oswaldo Aranha assumiu a Embaixada Brasileira em Washington e, já nessa época, é possível observar a gênese da política de barganhas que marcaria a diplomacia do período Vargas ${ }^{44}$. Devido à queda do preço do café, que se associou à impagável dívida assumida pelas administrações anteriores, as balanças comercial e financeira do país passaram a tender fortemente em direção a Washington; tal situação era contrabalançada pelo comércio com a Alemanha. Em suma, já no início da década de 1930, podia-se perceber a estratégia varguista de usar um certo nível de associação com os alemães, para refrear o avanço econômico e político americano sobre o Brasil.

Os anos de 1936 e 1937 são elucidativos de como funcionava, na prática, a estratégia de Getúlio. No primeiro destes anos, foi assinado um acordo de compensações que trocava produtos por produtos, eliminando a necessidade de moedas fortes como a libra e o dólar, escassos tanto no Brasil como na Alemanha ${ }^{45}$. Embora fossem expressivas as reclamações americanas, o acordo persistiu. No ano seguinte, foi instalado o Estado Novo, que, de imediato, suspendeu o pagamento da dívida externa; além disso, planejava-se uma forma de regular o envio de dinheiro para o exterior por parte das multinacionais instaladas no país. Neste momento, a imprensa americana e os interesses que haviam sido lesados com a suspensão do pagamento da dívida e com o acordo com os alemães clamavam por retaliações por parte do governo de Washington. É neste ponto que percebemos como um certo nível de associação com os alemães melhorava nossa condição de soberania diante dos americanos. Roosevelt foi o escudo brasileiro contra as pressões da opinião pública e dos trustes americanos, pois temia que

\footnotetext{
43 Historical Overview of U. S. Immigration Policy: The Period of Restriction, 1921-1964. In: http://www.cms.ccsd.k12.co.us/ss/SONY/Immbeta2/21-1964.htm.

${ }^{44}$ MOURA, G. Sucessos e Ilusões. Rio de Janeiro: Fundação Getúlio Vargas, 1991, p. 3.
} 
uma retaliação alinhasse definitivamente Brasil e Alemanha ${ }^{46}$. Embora conseguisse, ao longo do tempo, concessões importantes, a cada uma delas o Brasil se comprometia mais com o pan-americanismo. Até 1940, a situação continuou nesta ordem, a neutralidade era mantida por Getúlio, mesmo sob pressão de Aranha. Neste ano, Getúlio fez um discurso inflamado exaltando o nacionalismo e os interesses do país. Ao que parece, o discurso fez com que Washington, finalmente, resolvesse por ceder a tecnologia e os recursos necessários para a implantação da Siderúrgica Nacional. Tal fato marcou, na prática, o alinhamento definitivo do Brasil com os Estados Unidos, embora o Brasil ainda permanecesse neutro por mais de um ano.

Voltemos agora ao nosso "objeto" de reflexão. Não me parece racional considerar que Vargas pretendesse, de fato, alinhar Brasil e Alemanha no sentido político e ideológico. Não creio que pretendesse fazer do Brasil uma base americana para os alemães e, acima de tudo, creio que se algum aspecto da ideologia autoritária nazi-fascista atraía o estadista brasileiro, este aspecto restringia-se ao nacionalismo antiimperialista. Assim, considerar que a ideologia de ódio e exclusão racial que caracteriza o Terceiro Reich influenciou de forma determinante a restrição da entrada de judeus no Brasil, parece-me, por tudo o que li, absurdo e apaixonado. A Alemanha nazista em nenhum momento representou um modelo de identificação ideológica; em verdade, Vargas "via a Alemanha, como um instrumento de pressão para forçar os Estados Unidos a ceder às suas exigências ${ }^{47}$ ". Ao negar o reducionismo que explica toda a questão pela hipótese da germanofilia de Vargas, não pretendo dizer que dentro do corpo diplomático ou no Ministério das Relações Internacionais não existissem elementos germanófilos, e mesmo anti-semitas. O que pretendo questionar é o quanto estes elementos influíram na prática do processo imigratório. Ao fazer esta pergunta, somos obrigados a fazer ainda uma outra: houve mesmo um anti-semitismo verificável na prática dos órgãos diplomáticos brasileiros durante a era Vargas?

De fato, o ano de 1937 foi o único durante o período abordado pela autora em que a imigração judaica caiu enquanto a imigração em geral viu seus números aumentados $^{48}$. Em todos os outros anos, de 1930 a 1936 e de 1938 a 1945, todas as eventuais quedas nos números da imigração judaica acompanham quedas proporcionais

\footnotetext{
${ }^{45}$ Idem, p. 4.

${ }^{46}$ BANDEIRA, M. A Presença dos Estados Unidos no Brasil, p. 258.

${ }^{47}$ Idem, p. 283.

${ }^{48}$ LESSER, J. O Brasil e a Questão Judaica. Rio de Janeiro: Imago, 1995, p. 319.
} 
nos números gerais da imigração ${ }^{49}$. Não obstante a esse ano particular de restrições aplicadas aos "semitas", vemos em alguns outros anos que a quantidade de judeus imigrados era significativa demais para que aceitemos que ela convivesse harmoniosamente com uma mentalidade germanófila e anti-semita. Em 1936, os judeus representavam $26,7 \%$ do total de imigrantes entrados naquele ano. ${ }^{50}$

Em uma proposição também presente no livro de Tucci Carneiro, é colocado que a influência nazi-fascista e anti-semita se alargou no período do Estado Novo, entre 1937 e $1945^{51}$. Essa proposição torna-se inaceitável ao analisarmos os números referentes à imigração judaica para o Brasil nos anos de 1939, 1940 e 1941. Torna-se aqui indispensável lembrar ao leitor que o Brasil permaneceu neutro até 1942, mantendo relações diplomáticas com a Alemanha ${ }^{52}$. Não temos, por isso, motivos para acreditar que a suposta influência nazi-fascista aplicada à imigração tenha diminuído. Mesmo assim, os judeus representavam 20,2\% do fluxo imigratório no ano de 1939, eram $13,05 \%$ em 1940 e 15,0\% em 1941 ${ }^{53}$. Assim, considero que, se houve um antisemitismo aplicado à imigração no Brasil, ele não alcançou ao grupo judeu inteiro. Por isso, creio ser mais condizente com os arquivos que consideremos os casos isolados apresentados por Tucci Carneiro apenas como casos isolados. Em suma, podemos observar que no tocante à quantidade de vistos concedidos aos judeus que pretendiam e, posteriormente, entraram no Brasil, não é possível apontarmos um anti-semitismo atuante.

A autora observou cuidadosamente o texto das restrições à imigração, porém ignorou completamente os efeitos práticos que estas restrições desencadearam. Ou seja, o fato de ter se contentado com fontes selecionadas e que excluíram a necessidade ou a voz dos outros documentos que tratavam exatamente do mesmo tema, levou a autora a tratar de forma reducionista um tema de extrema complexidade e que envolve um número expressivo de variáveis. A prática de ocupar-se com fontes que compunham com sua hipótese, em detrimento de todos os outros documentos que não se encaixassem em tal hipótese, não é verificável apenas no confronto das circulares secretas com a prática imigratória. Ao tratar da postura da extrema direita com relação

\footnotetext{
${ }^{49}$ Idem.

${ }^{50}$ Ibidem.

${ }^{51}$ CARNEIRO, M. L. T. O Anti-semitismo na Era Vargas, p. 23.

${ }^{52}$ BANDEIRA, M. A Presença dos Estados Unidos no Brasil, p. 283.

${ }^{53}$ LESSER, J. O Brasil e a Questão Judaica, p. 319.
} 
aos judeus, a autora mais uma vez opta por fontes particularmente favoráveis aos seus propósitos, ignorando tudo o que está em volta delas.

Para alcançarmos a mentalidade dos grupos de extrema direita da época (e aqui tenho em mente, em primeiro lugar, o Integralismo), temos que retornar brevemente até a década de 1920. No plano da atividade política e cultural brasileira, a década de 1920 apontava claramente no sentido da afirmação nacional, o Integralismo nascia no Brasil como uma espécie de afirmação da nacionalidade.

Em verdade, o Integralismo não tinha uma ideologia única e nem contava com grandes financiadores, fatores que o diferem dos movimentos de direita europeus. Severino Sombra "pregava" um integralismo aplicado à prática e voltado para os problemas imediatos do povo, desemprego e injustiça social. Já Plínio Salgado e seus "camisas verdes" priorizavam o combate ao "fantasma" comunista e uma defensiva moral cristã renovada. É esta segunda vertente que mais interessa ao nosso propósito, pois bebia da fonte ideológica européia, transplantando preocupações que nem sempre se adaptavam à realidade brasileira. Tucci Carneiro dá especial atenção à produção jornalística e literária produzida por este pólo ideológico. Como escreve em um tópico dedicado ao tema, "o maior numero de obras anti-semitas publicadas durante a era Vargas é de autoria integralista ${ }^{54}$. . Dentro deste universo integralista, o anti-semita de maior expressão é Gustavo Barroso. Filho de mãe alemã e criado em um ambiente que acreditava nas linhas dos Protocolos dos Filhos de Sião, esse bacharel em Direito dispensou grande energia para chamar a atenção para a potencial dominação que o judeu buscava externar através da maçonaria, e na aplicação de capitais em áreas de potencial influência ideológica, como a política e a imprensa.

Mais uma vez, tornam-se claros os danos que o reducionismo interpretativo e o trato com os arquivos praticados pela autora causam à compreensão da questão judaica brasileira. Uma vez que, através de uma análise superficial das principais preocupações integralistas, notaremos que o anti-semitismo não tinha importância expressiva na estrutura ideológica do movimento. Assim, considerar que a mentalidade anti-semita, que não encontrou solo fértil mesmo dentro das limitadas fronteiras da extrema direita, tenha extrapolado tal área de influência e agido sobre o processo decisório que regia a imigração, me parece uma hipótese que não encontra sustentação em sua própria argumentação, e menos ainda nos arquivos.

\footnotetext{
${ }^{54}$ CARNEIRO,M. L. T. O Anti-semitismo na Era Vargas, p. 353.
} 
A importância periférica do anti-semitismo, dentro do ideário da extrema direita dos anos 30, é expresso, de forma esclarecedora, nas relações entre a cúpula do catolicismo e o Estado, e na proximidade entre as preocupações dos católicos e integralistas. Temos à nossa disposição um curto artigo a respeito das articulações da Igreja Católica, principalmente através dos congressos eucarísticos onde se procurava fundir catolicismo e identidade nacional. Intimamente associada tanto em ideologia, como em contra-ideologia, com o integralismo de Plínio Salgado - seria inconcebível um integralista engajado que não fosse católico -, o estudo das atitudes da Igreja Católica é elucidativo das preocupações principais de toda a extrema direita da época, dentre as quais, sob meu ponto de vista, não constava o elemento judeu.

Rita de Cássia Marques nos mostra que, a exemplo da AIB (Ação Integralista Brasileira), a preocupação principal da Igreja era o avanço das idéias comunistas. Embora fosse a "praga" que exigisse o "inseticida" católico-integralista, os comunistas não eram os únicos alvos da Igreja, a maçonaria, o protestantismo e o espiritismo também tiveram sua cota de atenção ${ }^{55}$. O que esclarece a nós, interessados na questão judaica, não é o que contém o artigo, e sim o que nele não se encontra. Mesmo discorrendo sobre um tema que envolve xenofobia, pensamento de extrema direita, perseguição política e religiosa, ideologia antiliberal, mesmo assim, na presença de tantos temas que permeiam a questão judaica, o grupo judeu não é sequer mencionado pela autora. Isso sugere que a questão judaica e o combate ativo ao elemento judeu eram temas um quanto insignificantes, mesmo para os que professavam o fascismo ideológico ou corporativo.

Em prevenção contra uma leitura reducionista de minhas palavras, creio ser necessária uma ressalva. Não pretendo dizer que não houvesse, tanto na AIB como na cúpula católica, mentes ocupadas com o afastamento dos judeus de território nacional. O que proponho é que o assunto não foi, em nenhum momento, uma prioridade de base para o ideário destes centros formadores de opinião. Por tudo isso, também Gustavo Barroso e seu anti-semitismo pouco popular podem ser entendidos como casos isolados.

Talvez, o reducionismo e a passionalidade de Tucci Carneiro tenham sido mais bem explicados pela revista Herança Judaica quando entrevistou o professor Izidoro Blikstein, docente de lingüística e semiótica na USP e especialista no fenômeno do

\footnotetext{
${ }^{55}$ MARQUES, R. C. A Igreja no Estado Novo: tempos de colaboração e intolerância. In: Caderno de Filosofia e Ciências Humanas, ano IV, n. 7, outubro 1996. Belo Horizonte: Ed. Faculdades Integradas Nilton Paiva, 1996.
} 
holocausto e em história judaica. A revista considerou que "embora competente historiadora, a autora desdenha a objetividade científica e cede à justa indignação humana pelas atitudes tomadas pelas autoridades brasileiras da época". A pergunta em questão, que cai como uma luva para o melhor entendimento do tema aqui tratado, era se o professor considerava que Tucci Carneiro "distinguia claramente entre xenofobia, racismo e anti-semitismo em seu livro ${ }^{56 "}$. A resposta do professor o alinha ao pensamento que desenvolvi sobre o tema, ao mesmo tempo em que resume o que falta no entendimento oferecido por Tucci Carneiro: "Quero crer que no período Vargas e mesmo depois, e ainda atualmente, possamos ter manifestações xenófobas sem serem anti-semitas."

\section{Síntese: Apontando caminhos}

Por fim, gostaria de citar um trecho de Roberto Grün que externa, de forma mais completa do que fiz - apesar de todas as minhas páginas -, a complexidade e a pluralidade de variáveis que envolvem a questão judaica brasileira:

Pra a mesma década de 1930, existe um debate sobre a questão do anti-semitismo na ditadura de Getúlio Vargas (1930-1945). Baseados na existência de restrições legais não públicas à imigração de judeus na época, alguns autores conferem um caráter anti-semita ao governo do período. Certamente, havia nas diversas agências do Estado indivíduos com convicções antijudaicas que poderiam exercê-las em suas funções, principalmente no corpo diplomático e no aparelho repressivo, então hipertrofiado. (...) Entretanto, dificilmente poderíamos distinguir as restrições impostas aos judeus daquelas impostas pelo governo norte-americano de Franklin Roosevelt, ou pelo governo britânico, no mesmo momento. Aliás, dada a flexibilização das regras estabelecidas "na prática” pelo governo brasileiro da época, pelas autoridades subalternas que faziam cumprir as determinações discricionárias, o Brasil acabou tornando-se um importante desaguadouro para o fluxo de judeus provenientes da Alemanha hitlerista, que encontravam fechadas as portas dos Estados Unidos. As entidades organizativas da diáspora tendo acumulado know-how no trato com governos que apresentavam modi operando parecidos, acabavam lidando bem com a informalidade na condução da política de imigração, conseguindo a entrada no Brasil de muitos imigrantes, bem além do que seria previsto pela simples aplicação da lei em vigor. Enfim, se compararmos a política do governo brasileiro em face dos judeus com aquela posta em prática em relação a outros povos, seja com as consideradas raças levantinas, como os assírios,

\footnotetext{
${ }^{56}$ Revista Herança Judaica, n. 73, 12/1998. São Paulo: Ed. B’noi B’rith s/c, 1988, p. 21.

${ }^{57}$ Idem.
} 
seja com os chineses, então chamados depreciativamente de cules, constatamos que a imigração dos últimos grupos era impedida por restrições muito mais severas e explícitas ${ }^{58}$.

Poderíamos ainda argumentar que as tais circulares secretas que impediam a entrada dos judeus nada mais eram que a expressão da contraposição estatal a uma máquina de corrupção instalada pelas agências do êxodo. Que além dos chineses, também os japoneses enfrentaram oposição, embora esta cedesse diante do caráter eminentemente rural destes. Teríamos ainda documentos que indicariam a hipótese de que o que realmente regia a imigração para o Brasil era a necessidade de agricultores que povoassem o vasto e inexplorado território.

Todos estes são caminhos que devem ser percorridos completamente antes que se construa um entendimento algo verossímil das pressões que definiam os parâmetros da imigração do governo Vargas.

\section{Considerações Finais}

Considero, finalmente, que através deste exemplo pude chamar a atenção dos humanistas para as possibilidades de projeções de sentido que circundam sua atividade. Assim, um retorno crítico do intérprete sobre suas próprias motivações é indispensável para uma escrita conscienciosa por parte dos interessados nas questões das humanidades. Afinal, "a história não é, obviamente, um sistema de alavancas mecânicas e inanimadas e automatismos de ferro e aço, e sim um sistema de pressões exercidas por pessoas vivas sobre pessoas vivas."

Considero cabível, como conclusão destas breves colocações, um alerta vindo da literatura: "Não esqueçamos que as causas das ações humanas costumam ser inumeravelmente mais complexas e diversas do que depois sempre as explicamos, e raramente se delineiam de maneira definida." ${ }^{60}$

\footnotetext{
${ }^{58}$ GRÜN, R. Construindo um lugar ao sol: os judeus no Brasil. In: FAUSTO, B (org.). Fazer a América: Imigração em massa para a América Latina. São Paulo: Ed. USP, 1999, pp. 372-4.

${ }^{59}$ ELIAS, N. A sociedade dos indivíduos. Rio de Janeiro: Jorge Zahar, 1994, p.47.

${ }^{60}$ DOSTOIÉVSKI, F. O Idiota. São Paulo: Ed. 34, 2002, p.47.
} 


\section{Bibliografia}

ARISTÓTELES, Ética a Nicômaco. Brasília: Ed. UnB, 1985.

BANDEIRA, M. A Presença dos Estados Unidos no Brasil. Rio de Janeiro: Civilização Brasileira, 1978.

BANN, S. As invenções da história: ensaios sobre a representação do passado. São Paulo: Ed. Unesp, 1994.

CARNEIRO, M. L. T. O Anti-semitismo na Era Vargas. São Paulo: Brasiliense, 1988.

DOSTOIÉVSKI, F. O Idiota. São Paulo: Ed. 34, 2002.

EINSTEIN, A. Como vejo o mundo. Rio de Janeiro: Nova Fronteira, 1981.

ELIAS, N. A Sociedade dos Indivíduos. Rio de Janeiro: Jorge Zahar, 1990.

FAUSTO, B. A Revolução de 1930: Historiografia e História. São Paulo: Cia das Letras, 1997.

FAUSTO, B. Fazer a América: Imigração em massa para a América Latina. São Paulo: Ed. USP, 1999.

FREUD, A. O Ego e os mecanismos de defesa. Rio de Janeiro: Civilização Brasileira, 1982.

FREUD, S. A interpretação dos Sonhos. Rio de Janeiro: Imago, 2001.

GADAMER, H. G. Verdade e Método. Petrópolis: Vozes, 1997.

GINZBURG, C. Relações de força: história, retórica e prova. São Paulo: Cia das Letras, 2002.

LESSER, J. O Brasil e a Questão Judaica. Rio de Janeiro: Imago, 1995.

MARQUES, R. C. A Igreja no Estado Novo: tempos de colaboração e intolerância. In: Caderno de Filosofia e Ciências Humanas, ano IV, n. 7, outubro 1996. Belo Horizonte: Ed. Faculdades Integradas Nilton Paiva, 1996.

MOURA, G. Sucessos e Ilusões. Rio de Janeiro: Fundação Getúlio Vargas, 1991.

NOVAES, A. Tempo e História. São Paulo: Cia das Letras, 1992.

PESAVENTO, S. J. (Org.). Fronteiras do milênio. Porto Alegre: Ed. UFRGS, 2001.

REALE, G. História da Filosofia. São Paulo: Paulus, 2000, vol. I.

RENOUVIN, P. e DUROSELlE, J. B. Introdução à História das Relações Internacionais. São Paulo: Difusão Européia do Livro, 1967.

SCHORSKE, C. F. Pensando com a história: indagações na passagem do modernismo. São Paulo: Cia das Letras, 2000. 
SELLERS, C. Uma Reavaliação da História dos Estados Unidos. Rio de Janeiro: Jorge Zahar Editor, 1985.

SWAIN, T. N. (org.) História no Plural, Brasília: Ed. UNB, 1993.

WHITE, H. Trópicos do Discurso: ensaios sobre a crítica da cultura. São Paulo: Ed. USP, 1994. 